\title{
Recent advances and emerging therapies in anaplastic
}

\section{thyroid carcinoma [version 1; peer review: 3 approved]}

\author{
Maria E. Cabanillas (D1, Mark Zafereo², Michelle D. Williams³, Renata Ferrarotto4, \\ Ramona Dadu1, Neil Gross², G. Brandon Gunn ${ }^{5}$, Heath Skinner ${ }^{5}$, Gilbert Cote1, \\ Horiana B. Grosu6, Priyanka Iyer ${ }^{1}$, Naifa L. Busaidy ${ }^{1}$
}

\begin{abstract}
${ }^{1}$ Department of Endocrine Neoplasia \& Hormonal Disorders, The University of Texas MD Anderson Cancer Center, 1515 Holcombe Blvd, Houston, TX, 77030, USA

2Department of Head and Neck Surgery, The University of Texas MD Anderson Cancer Center, 1515 Holcombe Blvd, Houston, TX, 77030, USA

${ }^{3}$ Department of Pathology, The University of Texas MD Anderson Cancer Center, 1515 Holcombe Blvd, Houston, TX, 77030, USA

${ }^{4}$ Department of Thoracic Head and Neck Medical Oncology, The University of Texas MD Anderson Cancer Center, 515 Holcombe Blvd, Houston, TX, 77030, USA

${ }^{5}$ Department of Radiation Oncology, The University of Texas MD Anderson Cancer Center, 1515 Holcombe Blvd, Houston, TX, 77030, USA

${ }^{6}$ Department of Pulmonary Medicine, The University of Texas MD Anderson Cancer Center, 1515 Holcombe Blvd, Houston, TX, 77030, USA
\end{abstract}

V1 First published: 18 Jan 2018, 7(F1000 Faculty Rev):87

https://doi.org/10.12688/f1000research.13124.1

Latest published: 18 Jan 2018, 7(F1000 Faculty Rev):87

https://doi.org/10.12688/f1000research.13124.1

\section{Abstract}

Anaplastic thyroid cancer is a rare and aggressive thyroid cancer with an overall survival measured in months. Because of this poor prognosis and often advanced age at presentation, these patients have traditionally been treated palliatively and referred for hospice. However, recent progress using novel therapies has energized the field, and several promising clinical trials are now available for these patients. This review will highlight this progress and the potential treatments that could pave the way to improved outcomes and quality of life for patients with this disease.

\section{Keywords}

BRAF, dabrafenib, trametinib, vemurafenib, squamous, sarcomatoid, anaplastic thyroid cancer, dedifferentiated, undifferentiated, targeted therapy, chemotherapy, NTRK

\section{Open Peer Review \\ Approval Status \\ 12 \\ 23 \\ version 1 \\ 18 Jan 2018 \\ Faculty Reviews are review articles written by the prestigious Members of Faculty Opinions. The articles are commissioned and peer reviewed before publication to ensure that the final, published version is comprehensive and accessible. The reviewers who approved the final version are listed with their names and affiliations.}

1. Ana O Hoff, Instituto do Câncer do Estado de São Paulo, São Paulo, Brazil

2. Vera Tiedje, University Hospital Essen and University Duisburg-Essen, Essen, Germany 


\section{Ashok R Shaha, Memorial Sloan Kettering \\ Cancer Center, New York, USA}

Any comments on the article can be found at the end of the article.

Corresponding author: Maria E. Cabanillas (mcabani@mdanderson.org)

Author roles: Cabanillas ME: Conceptualization, Writing - Original Draft Preparation; Zafereo M: Writing - Review \& Editing; Williams MD: Writing - Review \& Editing; Ferrarotto R: Writing - Review \& Editing; Dadu R: Writing - Review \& Editing; Gross N: Writing - Review \& Editing; Gunn GB: Writing - Review \& Editing; Skinner H: Writing - Review \& Editing; Cote G: Writing - Review \& Editing; Grosu HB: Writing - Review \& Editing; Iyer P: Writing - Review \& Editing; Busaidy NL: Writing - Review \& Editing

Competing interests: MEC has received research funding from Roche Genentech, Kura, Eisai, and Exelixis. MEC has also received consultant fees from LOXO. NLB has received research funding from Bayer and Novartis and consulting fees from Eisai and Sanofi. BG, MDW, HS, PI, NG, RF, HG, and MZ have nothing to disclose.

Grant information: The author(s) declared that no grants were involved in supporting this work.

Copyright: $@ 2018$ Cabanillas ME et al. This is an open access article distributed under the terms of the Creative Commons Attribution License, which permits unrestricted use, distribution, and reproduction in any medium, provided the original work is properly cited.

How to cite this article: Cabanillas ME, Zafereo M, Williams MD et al. Recent advances and emerging therapies in anaplastic thyroid carcinoma [version 1; peer review: 3 approved] F1000Research 2018, 7(F1000 Faculty Rev):87

https://doi.org/10.12688/f1000research.13124.1

First published: 18 Jan 2018, 7(F1000 Faculty Rev):87 https://doi.org/10.12688/f1000research.13124.1 


\section{Introduction}

Anaplastic thyroid carcinoma (ATC) is a rare form of thyroid cancer and one of the most aggressive cancers in humans. In part because of ATC's rarity and short overall survival, very little progress has been made in the treatment of this disease until recently. An understanding of the molecular aberrations in this disease has advanced the field, leading to one of the most important treatment discoveries-BRAF targeting in BRAF V600E-mutant ATC. While this is an exciting discovery and represents substantial progress, only $25-45 \%$ of ATCs harbor a $B R A F$ mutation $^{1-3}$, and this treatment is not curative. However, a renewed interest in this disease will likely lead to a deeper comprehension of the mechanisms by which these tumors survive, that one day may result in better therapies and eventually a cure for this devastating disease.

\section{Background}

The usual clinical presentation of ATC is of a patient with a rapidly expanding neck mass that may lead to compressive symptoms such as dysphagia and dyspnea. Patients may also have hoarseness due to vocal cord paralysis secondary to laryngeal nerve paralysis that can progress to stridor. However, some patients may have few symptoms until the disease is quite advanced and, therefore, most patients with ATC are not surgical candidates. Furthermore, approximately $46 \%$ of newly diagnosed patients present with widely metastatic disease at diagnosis ${ }^{4}$. Patients may give a past history of long-standing goiter, thyroid nodules, or prior thyroid cancer. According to one series, in more than $80 \%$ of cases, there is a co-existing differentiated thyroid cancer (DTC) giving rise to a less differentiated or undifferentiated tumor ${ }^{5}$.

The diagnosis of ATC can be made on fine needle aspiration, core biopsy, or surgical resection material. Fine needle aspiration is often the first attempt at biopsy, since this is the standard of care for thyroid nodules and suspected thyroid cancers. However, if the diagnosis of ATC is suspected, a core needle biopsy is preferable in order to perform genetic mutational analysis of the tumor. Many patients are not suspected to have ATC and are diagnosed only after undergoing thyroidectomy when the surgical pathology is reviewed.

The differential diagnosis of ATC includes lymphoma, poorly differentiated thyroid carcinoma (PDTC), poorly differentiated medullary thyroid carcinoma (MTC), squamous cell carcinoma from an adjacent site, and metastasis from other solid tumors. The diagnosis can be challenging because of the frequent loss of thyroid (TTF-1 and PAX8) and epithelial cell markers (cytokeratins). Morphologically, ATC is highly variable, from sarcomatoid, squamoid, and epithelioid to pleomorphic/giant cell cytologic features. ATC often grows as discohesive sheets of overtly malignant cells with high-grade features including marked necrosis and mitoses. An associated mixed inflammatory component is also present in the background.

According to the American Joint Committee on Cancer (AJCC) thyroid cancer staging system $^{6}$, all ATC patients are considered to have stage IV disease owing to the extremely high mortality rate. Stage IV disease is further broken down into stage IVA (intrathyroidal and surgically resectable without distant metastatic disease), stage IVB (extrathyroidal, with or without lymph node metastases but without distant metastatic disease), and stage IVC (distant metastatic disease at presentation).

Overall prognosis for ATC remains poor despite recent advances. The median overall survival remains around 3-5 months with a 1 -year survival of approximately $20 \%{ }^{7}$. Patient factors associated with poorer prognosis include advanced age ( $>60-70$ years), male gender, presence of leukocytosis $(>10,000)$, and symptoms (such as rapidly growing tumor, pain in the neck, dyspnea, dysphagia, and hoarseness). Histologically, larger tumor size $(>5 \mathrm{~cm})$, extrathyroidal invasion, giant cell and pleomorphic pattern, and/or presence of distant metastases are tumor factors that can portend a poor survival and predict treatment failure. Tumors with co-existing well-differentiated papillary thyroid carcinoma appear to fare better ${ }^{2,7-9}$. In terms of treatment factors, patients with tumors that are surgically resectable and who are able to undergo external beam radiation have improved survival ${ }^{4,8-16}$. The dose of external beam radiation is also prognostic, with patients who are able to undergo higher doses ( $>60 \mathrm{~Gy}$ ) surviving longer, even those who have not undergone complete resection ${ }^{12,17}$. Somatic tumor mutations may also affect outcomes. ATC tumors with TERT promotor mutations had a significantly shorter overall survival, particularly when these co-existed with either $B R A F$ or $R A S$ mutations ${ }^{1}$. In another study, ATC patients with TP53 mutations were shown to have a trend towards shorter time to failure after primary treatment ${ }^{2}$.

Standard treatment for patients with stage IVA disease and some IVB patients is curative intent surgery, as this has been associated with longer survival ${ }^{10,14,18-20}$. Surgery should be performed by a surgeon with experience in advanced thyroid cancer. Post-operative radiation with radiosensitizing chemotherapy should be started within 4 weeks of surgery. Chemotherapy regimens are detailed in the American Thyroid Association guidelines for the management of patients with ATC ${ }^{21}$. Unfortunately, surgery is not possible in the majority of patients, as most present with locally advanced and invasive disease. In general, if the patient has unresectable IVB disease, chemoradiation can be considered with the goal of local control. If the radiation field is too large or the chemoradiation treatment deemed too morbid for the patient, systemic therapy can be considered in these patients, particularly the novel targeted treatments discussed in the next section. Patients with IVC disease are the most challenging to manage, as balancing the need to control both local and distant metastatic disease can be difficult. Treatment guidelines recommend palliative radiation to control locoregional disease; however, our experience has been that palliative radiation provides little control. Thus, our practice is to treat these patients on clinical trials (preferable) or outside a trial with novel targeted therapies. A better understanding of the genetics of thyroid cancers has led to the use of novel therapies for ATC, which is the theme of this manuscript.

\section{Genetics of anaplastic thyroid cancer}

The MAP kinase and PI3 kinase pathways are commonly activated in thyroid cancer. The common driver mutations that are 
seen in ATC are the same as those in DTC, as these tumors are usually derived from this class of tumor, particularly papillary, follicular, and Hurthle cell thyroid cancers. Thus, BRAF, NRAS, $K R A S$, and HRAS are common driver mutations seen in ATC. Mutations in tumor suppressor genes include $p 53, N F 1$, and PTEN. Secondary mutations such as PIK3CA, TERT promotor, CTNNB1, EIF1AX, MTOR, CDKN2A, and AKT1 can co-exist with driver mutations and tumor suppressor gene mutations. Figure 1 shows the frequency of point mutations in ATC. The genetic rearrangements observed in papillary thyroid cancer, RET/PTC and NTRK, have also been described in ATC. Most recently, $A L K$ and ROS1 genetic rearrangements have also been described ${ }^{22,23}$.

Of all of the genetic mutations that occur in ATC, BRAF V600E is the most common $\left(25-48 \%{ }^{1-3,24}\right)$ actionable mutation, and therefore the most is known regarding novel therapies that target this mutation in ATC. However, other rare mutations and genetic aberrations may also prove to be actionable, such as $A L K$ translocations. Unfortunately, at this time, the majority of mutations in ATC are not actionable, but targeting of the tumor microenvironment or common pathways is an alternative approach. Figure 2 shows drugs and drug targets of interest in thyroid cancer.

\section{Novel and promising therapies for ATC}

Targeting genetic aberrations

BRAF inhibitors. Several case reports of responses in BRAFmutated ATC to selective BRAF inhibitors sparked interest in using these drugs in this disease ${ }^{25-27}$. Two basket trials that included $B R A F$-mutant ATC have been reported. The first trial reported had a very small cohort of ATC patients $(n=7)$ treated with vemurafenib $^{28}$. In this study, one complete response (CR) and one partial response (PR) were reported. These two patients had relatively long responses and survival, as one was alive at the time of data cut-off after 12.7 months and the other lived for 15.5 months after starting the trial. Vemurafenib is FDA approved for use in the treatment of melanoma.

A basket trial with the selective BRAF inhibitor dabrafenib combined with the MEK inhibitor trametinib has, by far, reported the largest cohort of BRAF inhibitor-treated ATC patients ${ }^{29}$. This trial was designed to enroll $B R A F$-mutated patients with nine different histologies, including an ATC cohort. Cohorts showing promising results were expanded. A total of $16 B R A F$-mutated ATC patients, all previously treated with radiation or surgery, were reported; 11 of the 16 patients achieved PR. The median PFS and OS were not reached but were estimated to be $79 \%$ and $80 \%$ at 1 year, respectively. The most common adverse events were fatigue, pyrexia, and nausea. The combination of dabrafenib and trametinib is approved for $B R A F$-mutated melanoma and squamous cell carcinoma of the lung and has received Breakthrough Therapy Designation by the Food and Drug Administration for ATC.

The advantage of selective BRAF/MEK inhibitors is how rapidly these drugs can start to take effect. We previously published a case report of a $B R A F$-mutated ATC patient who failed several

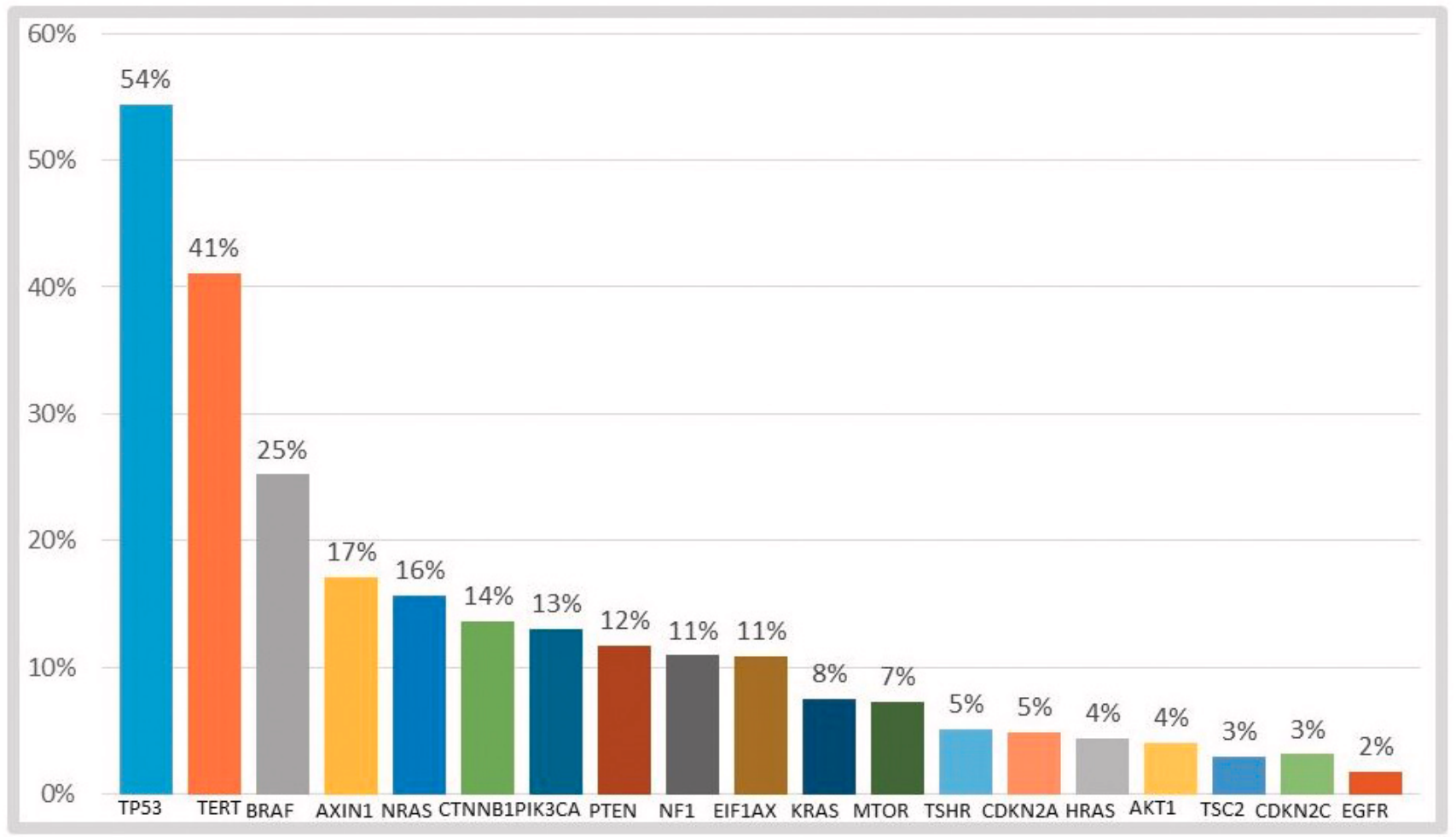

Figure 1. Distribution of oncogenic mutations in anaplastic thyroid carcinoma. Data compiled from three sources: COSMIC (cancer. sanger.ac.uk $)^{3}$, Kunstman et al. ${ }^{24}$, and Landa et al. ${ }^{1}$. Genetic rearrangements are not represented on the graph. 


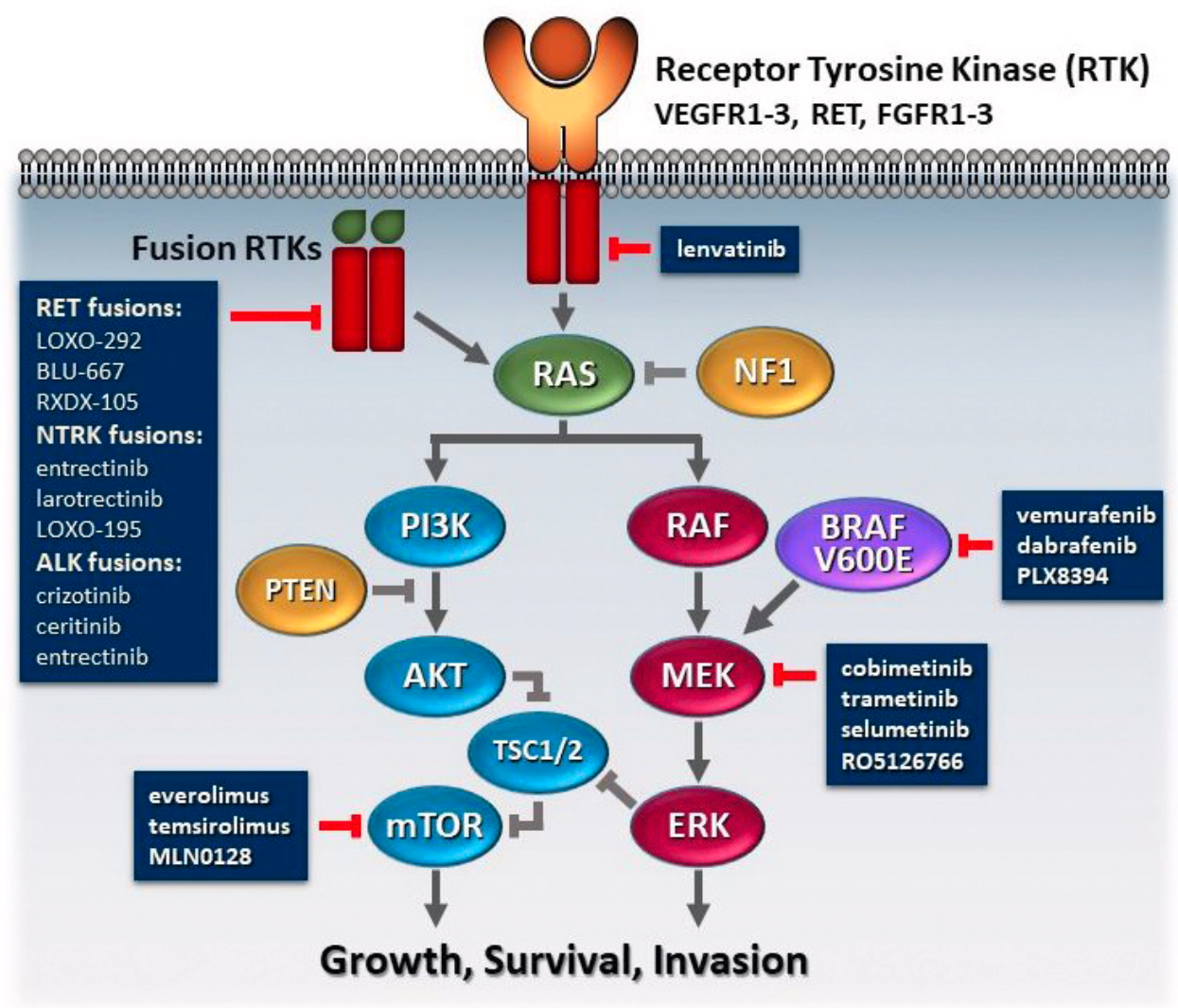

Figure 2. Schematic overview of the two most common pathways with genetic alterations in thyroid cancer-mitogen-activated protein kinase (MAPK) and phosphatidylinositide 3-kinase (PI3K) pathways. The pathways can be activated by receptor tyrosine kinases (RTKs) being activated by growth factors or by overexpression of the receptor. Constitutive activation of the signaling pathways can be caused by mutations along the pathway, such as BRAF, RAS, PI3K, AKT, or mammalian target of rapamycin (mTOR), mutations in tumor suppressor genes, such as neurofibromin 1 (NF1) or phosphatase and tensin homolog (PTEN) mutations, or fusion RTKs, such as those in RET, neurotropic tropomyosin receptor kinase (NTRK), or anaplastic lymphoma kinase (ALK). Drugs that can inhibit at critical points in the pathway are listed in grey boxes. FGFR, fibroblast growth factor receptor; TSC1, tuberous sclerosis complex 1; TSC2, tuberous sclerosis complex 2; VEGFR, vascular endothelial growth factor receptor.

lines of therapy ${ }^{26}$. The patient had stridor from significant airway obstruction prior to starting compassionate-use dabrafenib plus trametinib. This treatment prevented tracheostomy, and imaging performed 1 month after initiating treatment showed a dramatic response to therapy with a patent airway. Another way that the rapid onset of this combination therapy can be harnessed is by using these drugs as neoadjuvant therapy to shrink the tumor prior to surgery. Neoadjuvant vemurafenib has been studied in papillary thyroid cancer, and this strategy was deemed safe ${ }^{30}$. In ATC, neoadjuvant BRAF plus MEK inhibitors could prove to be useful in patients with stage IVB disease, leading to regression and thereby allowing for complete surgical resection. Further studies are needed to determine if neoadjuvant treatment will result in improved locoregional control and/or survival.

NTRK inhibitors. There are two NTRK inhibitors at this time in clinical trials. Larotrectinib (LOXO) is a selective pan-TRK inhibitor that is highly potent against TRKA, B, and C. Trial results of three separate studies that included a total of 55 patients with
NTRK fusions were reported at the American Society of Clinical Oncology (ASCO) Annual Meeting in 2017. There were 17 unique tumor types, including $9 \%$ thyroid cancer patients. The response rate in the 55-patient cohort was 78\%, with four thyroid cancer patients achieving PR and one achieving CR. The histology of these five thyroid cancer patients was not reported. The drug was deemed tolerable, with fatigue, dizziness, anemia, and vomiting being the most common adverse events. Entrectinib (RXDX-101) is another pan-TRK inhibitor but also targets $A L K$ and ROS1 fusions. The drug is being studied in a basket trial for patients with NTRK, ALK, or ROS genetic rearrangements (NCT02568267). Results from the phase I trial have been reported; however, there were no thyroid cancer patients treated on this trial ${ }^{31}$. Central nervous system activity was reported in one patient with NTRK fusion lung cancer who achieved CR in the brain.

Alk and ROS1 inhibitors. ALK mutations and fusions are uncommon events in thyroid cancer. They have been reported in $1.6 \%$ of papillary thyroid cancers, $4 \%$ of ATCs, and $9 \%$ of PDTCs in 
one series ${ }^{22}$. Only one case of a thyroid cancer patient with $A L K$ fusion treated with an ALK inhibitor has been reported in the literature. The patient was treated with crizotinib after failing standard therapy for ATC and achieved a remarkable response ${ }^{32}$. A trial with ceritinib for $A L K$ mutation or fusion is underway (NCT02289144). Only one case of ROS1 rearrangement in papillary thyroid cancer has been reported. Although it has not been reported in ATC, it is possible that these exist in patients with ATC transformed from papillary thyroid cancer. Entrectinib (discussed above) is a pan-TRK, ALK, and ROS1 inhibitor that will be investigated in thyroid cancer patients in a currently enrolling basket trial (NCT02568267).

mTOR inhibitors. Targeting of MTOR, which is in the PI3 kinase pathway, has proven successful in other solid tumors such as renal cell carcinoma. Activating mutations along this pathway (Figure 1), including PIK3CA and MTOR, as well as tumor suppressor loss of regulatory function mutations in PTEN, TSC1, and TSC2, are seen in ATC. NF1 is another potential target of mTOR inhibitors, as NF1-mutated tumors can signal down the PI3 kinase pathway. Everolimus is the mTOR inhibitor most studied in thyroid cancer $^{33-35}$. Several of these trials have included small numbers of ATC patients, but only occasional responses have been seen to date. One very impressive response was seen in a patient with a TSC2 mutation. This patient responded to everolimus for 18 months before developing progression. Analysis of the tumor at progression revealed a new MTOR mutation ${ }^{36}$. A study of a second-generation mTOR inhibitor with broad-spectrum inhibition of the mTOR complex is currently enrolling ATC patients (NCT02244463).

\section{Targeting the tumor microenvironment}

Antiangiogenics. Antiangiogenics are effective in DTCs and MTCs, and lenvatinib, sorafenib, vandetanib, and cabozantinib are FDA approved for these indications. These and other antiangiogenics ${ }^{37-40}$ have also been studied in ATC, but only one antiangiogenic drug, lenvatinib, has shown sufficient efficacy to warrant further study as a single agent in a phase II trial. Lenvatinib was studied in a trial that included all three thyroid cancer types in $\mathrm{Japan}^{41}$. This trial enrolled 17 ATC patients. Four patients (24\%) achieved PR, $12(71 \%)$ had stable disease, and one $(6 \%)$ had progression as their best response. The median PFS in the ATC cohort was 7.4 months (95\% CI: 1.7-12.9) and the median OS was 10.6 months (95\% CI: 3.8-19.8). However, only 10 of the 17 tumors were centrally confirmed to be ATC. The favorable results of this study led to a larger, international, phase II trial to test the efficacy of lenvatinib in ATC (NCT02657369).

Another interesting trial that holds promise is a study with intensity modulated radiotherapy with radiosensitizing chemotherapy plus or minus pazopanib (randomly assigned; NCT01236547). This study - the first trial in ATC to complete anticipated enrollmentclosed to new patient enrollment in 2016. The primary endpoint is OS; thus, the results are not expected until 2018.

Immunotherapy. At this time, there are no trial reports using immunotherapy in ATC. However, many immunotherapy trials for ATC are currently recruiting patients. Immunoprofiling of ATC tumors has shown that tumor-infiltrating lymphocytes are present in high numbers and that these tumors express programmed deathligand 1 (PD-L1), which plays a role in suppressing the immune system $^{42-46}$. Previous small studies have shown that tumorassociated macrophages (TAMs) are present in high frequencies in ATC compared with PDTC and DTC. Increased TAMs are associated with more invasive cancers and decreased survival, suggesting a tumorigenic role of TAMs in these cancers ${ }^{47-49}$. Although limited data exist with regard to functional characterization of TAMs, it is thought that TAMs closely resemble M2 (protumoral macrophages). In other cancer types, it has been shown that TAMs express programmed cell death-1 (PD-1), suggesting that PD-1/PD-L1 therapies may also function through a direct effect on macrophages ${ }^{50}$. Additionally, TAM-focused therapeutic strategies could synergize with immunotherapy.

Several checkpoint inhibitors that target PD-1 or its ligand, PD-L1, are approved for other cancers. However, given our experience, because of the rate at which ATC tumors expand and the usually large size of ATC tumors, we believe that these drugs will require combination therapy with kinase inhibitors, cytotoxic chemotherapy, or radiation. In an immunocompetent mouse model of BRAF/p53-mutated ATC, the combination of a BRAF inhibitor plus anti-PD-L1 drugs led to far better responses than either drug alone ${ }^{51}$, suggesting that combination therapy should be pursued in clinical trials. A clinical trial using this approach is currently underway (NCT03181100), as are other trials using combination checkpoint inhibitors (NCT03246958) and radiation plus immunotherapy (NCT03122496 and NCT03211117).

\section{Summary of the evolving management and future directions in ATC}

Owing to the staggeringly high failure rate in ATC and recent renewed interest in this disease, new paradigm shifts are rapidly evolving and being adopted by many leaders in the field. While routine molecular testing of ATC tumors is not currently in treatment guidelines and is controversial, our group feels strongly that all of these patients' tumors should be tested upon diagnosis, at minimum, to determine BRAF status. Patients with $B R A F$ mutations can be offered treatment with combination selective BRAF plus MEK inhibitor therapy. Some patients with initially unresectable disease may become resectable and could be considered for surgery if they respond to BRAF/MEK combination therapy. Patients who are well enough and want to consider clinical trials should have a broader panel of mutations and fusions interrogated in order to identify those who would be appropriate for selective inhibitor trials such as the selective NTRK or RET inhibitor trials. Other driver mutations that are identified may help identify a clinical trial that is appropriate for the patient, particularly as more targeted therapies become available. Figure 3 shows a proposed algorithm for selecting treatment in ATC patients and how the molecular information of the tumor can be used to help guide therapy, particularly in patients with a BRAF V600E mutation, since currently the most promising treatments are in these patients.

However, in order for patients to begin therapy before they deteriorate clinically, it is necessary to be able to rapidly test patients 
Initial Steps to Determine the Optimal Treatment in ATC

1. Airway assessment: Laryngoscopy

2. Determine if there are distant metastases: Staging images

3. Determine BRAF status: Biopsy followed by rapid BRAF testing
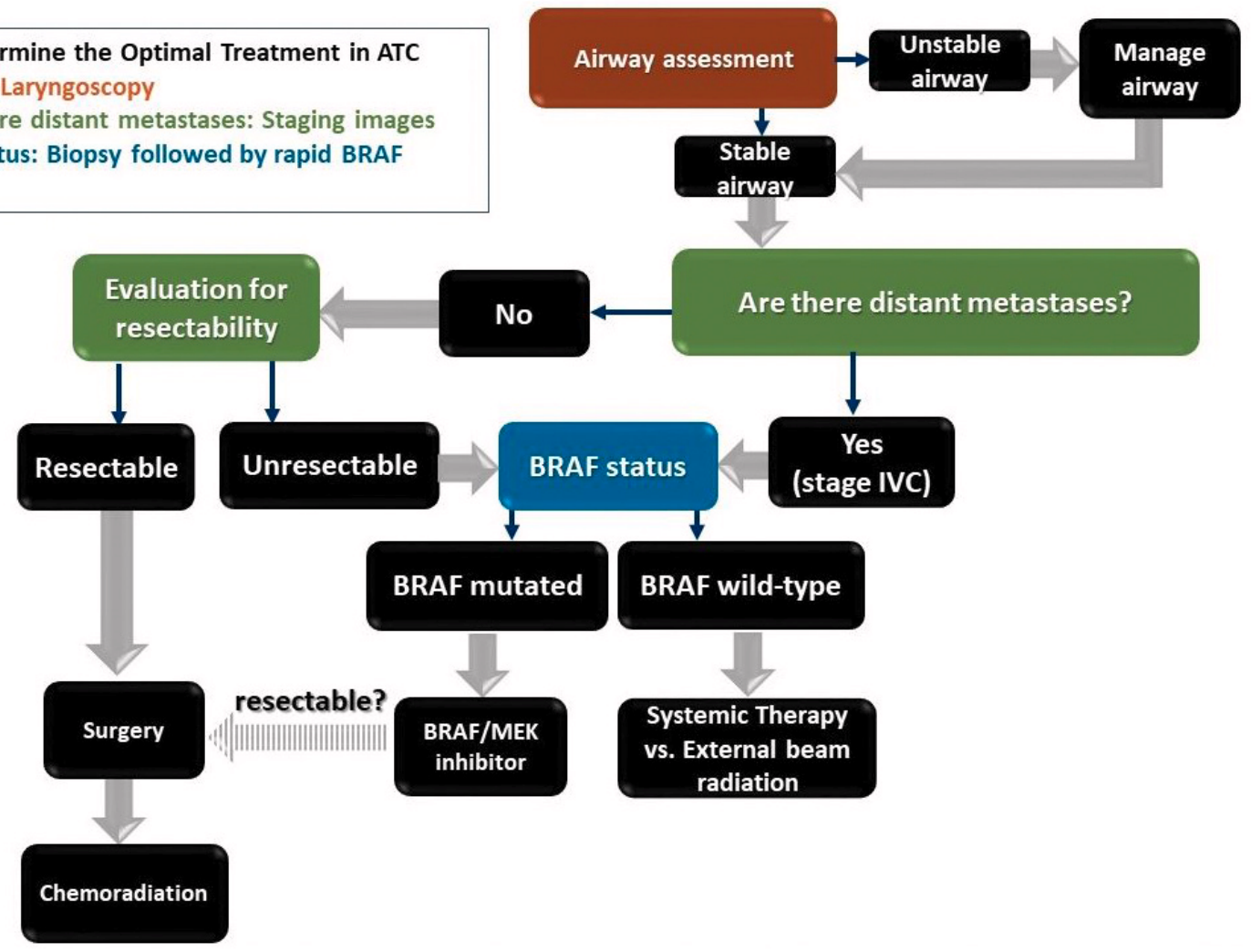

Figure 3. Proposed algorithm to determine best treatment in anaplastic thyroid carcinoma (ATC). The most critical steps that lead to important decision points are in colored boxes and should be performed in tandem. Brown box: the airway should also be assessed by laryngoscopy. An unstable airway will require immediate management, which might include steroids, intubation, tracheostomy, or hospice if the patient has a poor performance status. Green boxes: full staging with cross-sectional, contrast-enhanced imaging of the brain, neck, chest, and abdomen as well as bone scan or PET/CT (preferable) should be performed in order to determine if there are distant metastases. If brain metastases are present, these may require radiation or surgery prior to any therapy. Based on the staging images and the patient's performance status, the patient should be evaluated to determine if the tumor is resectable and a good surgical candidate. Blue box: a rapid test to determine BRAF status should be performed as soon as possible. Patients with a stable airway can be triaged to BRAF-directed therapy if a BRAF V600E mutation is present. If there is a treatment response that leads to resectability, surgery by an experienced surgeon may be considered for patients with low burden or no distant metastatic disease. In the absence of a BRAF V600E mutation, external beam radiation to the neck or systemic therapy on clinical trial is recommended. The decision between systemic therapy and external beam radiation in the BRAF wild-type subgroup will depend on local versus distant disease burden.

for pertinent mutations. The gold standard of molecular testing with next-generation sequencing can take over 1 month before results are known (far too long for patients with a rapidly lethal disease). Thus, the use of liquid biopsy, the testing of blood for circulating cell-free tumor DNA, which has been shown to be highly sensitive for identifying $B R A F$ mutations in circulating DNA, should be employed routinely in patients who do not have available tissue specimens ${ }^{52}$. In those with available tissue, immunohistochemistry for BRAF V600E on surgical specimens or core needle biopsy has proven to be a useful, rapid tool to identify BRAF-mutated ATC patients ${ }^{53}$.

Resistance to kinase inhibitors remains a major obstacle in the treatment of ATC. Thus, moving away from single-agent therapy for ATC is one step in the right direction. Combinations of targeted therapy with immunotherapy may help overcome resistance and are currently being studied in clinical trials. Radiation plus systemic therapy with either immunotherapy or targeted therapies are also promising strategies for ATC patients. Also, due to the very high recurrence rate after definitive treatment with surgery and radiation, a systemic adjuvant approach should be studied in this setting.

The future is much more promising for ATC patients; however, many physicians continue to recommend hospice as the only option for these patients. Our hope in the current environment with potential promising targeted therapies is that more patients are aware of and will participate in clinical trials, particularly those whose tumors are molecularly driven. Increasing medical and public awareness of expanding clinical trial options for ATC, coupled with 
enhanced availability of tumor sequencing, may prime a cycle for rapid enrollment and outcome data in this rare disease.

\section{Competing interests}

MEC has received research funding from Roche Genentech, Kura, Eisai, and Exelixis. MEC has also received consultant fees from LOXO. NLB has received research funding from Bayer and Novartis and consulting fees from Eisai and Sanofi. BG, MDW, HS, PI, NG, RF, HG, and MZ have nothing to disclose.

\section{Grant information}

The author(s) declared that no grants were involved in supporting this work.
1. $\quad \mathrm{F}$ Landa I, Ibrahimpasic T, Boucai L, et al.: Genomic and transcriptomic hallmarks of poorly differentiated and anaplastic thyroid cancers. J Clin Invest. 2016; 126(3): 1052-66.

PubMed Abstract | Publisher Full Text | Free Full Text | F1000 Recommendation

2. Rao SN, Zafereo M, Dadu R, et al:: Patterns of Treatment Failure in Anaplastic Thyroid Carcinoma. Thyroid. 2017; 27(5): 672-81.

PubMed Abstract | Publisher Full Text

3. Forbes SA, Beare D, Gunasekaran P, et al.: CosMIC: exploring the world's knowledge of somatic mutations in human cancer. Nucleic Acids Res. 2015; 43(Database issue): D805-11.

PubMed Abstract | Publisher Full Text | Free Full Text

4. Mclver B, Hay ID, Giuffrida DF, et al:: Anaplastic thyroid carcinoma: a 50-year experience at a single institution. Surgery. 2001; 130(6): 1028-34. PubMed Abstract | Publisher Full Text

5. Aldinger KA, Samaan NA, Ibanez M, et al:: Anaplastic carcinoma of the thyroid: a review of $\mathbf{8 4}$ cases of spindle and giant cell carcinoma of the thyroid. Cancer. 1978; 41(6): 2267-75.

PubMed Abstract | Publisher Full Text

6. Greene FL, Page DL, Fleming ID, et al.: AJCC cancer staging manual. 6th edition. New York: Springer; 2002.

Publisher Full Text

7. Kebebew E, Greenspan FS, Clark $\mathrm{OH}$, et al.: Anaplastic thyroid carcinoma Treatment outcome and prognostic factors. Cancer. 2005; 103(7): 1330-5. PubMed Abstract | Publisher Full Text

8. Kim TY, Kim KW, Jung TS, et al:: Prognostic factors for Korean patients with anaplastic thyroid carcinoma. Head Neck. 2007; 29(8): 765-72. PubMed Abstract | Publisher Full Text

9. Sugitani I, Miyauchi A, Sugino K, et al.: Prognostic factors and treatment outcomes for anaplastic thyroid carcinoma: ATC Research Consortium of Japan cohort study of 677 patients. World J Surg. 2012; 36(6): 1247-54. PubMed Abstract | Publisher Full Text

10. Haigh $\mathrm{PI}$, Ituarte $\mathrm{PH}, \mathrm{Wu} \mathrm{HS}$, et al.: Completely resected anaplastic thyroid carcinoma combined with adjuvant chemotherapy and irradiation is associated with prolonged survival. Cancer. 2001; 91(12): 2335-42. PubMed Abstract | Publisher Full Tex

11. F Prasongsook N, Kumar A, Chintakuntlawar AV, et al:: Survival in Response to Multimodal Therapy in Anaplastic Thyroid Cancer. J Clin Endocrinol Metab. 2017; 102(12): 4506-14.

PubMed Abstract | Publisher Full Text | F1000 Recommendation

12. F Glaser SM, Mandish SF, Gill BS, et al.: Anaplastic thyroid cancer: Prognostic factors, patterns of care, and overall survival. Head Neck. 2016; 38 Suppl 1: E2083-90. PubMed Abstract | Publisher Full Text | F1000 Recommendation

13. Pierie JP, Muzikansky A, Gaz RD, et al:: The effect of surgery and radiotherapy on outcome of anaplastic thyroid carcinoma. Ann Surg Oncol. 2002; 9(1): 57-64. PubMed Abstract | Publisher Full Text

14. Kihara M, Miyauchi A, Yamauchi A, et al.: Prognostic factors of anaplastic thyroid carcinoma. Surg Today. 2004; 34(5): 394-8.

PubMed Abstract | Publisher Full Text

15. Are C, Shaha AR: Anaplastic thyroid carcinoma: biology, pathogenesis, prognostic factors, and treatment approaches. Ann Surg Oncol. 2006; 13(4): 453-64.

PubMed Abstract | Publisher Full Text

16. Akaishi J, Sugino K, Kitagawa W, et al.: Prognostic factors and treatment outcomes of 100 cases of anaplastic thyroid carcinoma. Thyroid. 2011; 21(11): 1183-9.

PubMed Abstract | Publisher Full Text

17. Pezzi TA, Mohamed AS, Sheu T, et al:: Radiation therapy dose is associated with improved survival for unresected anaplastic thyroid carcinoma: Outcomes from the National Cancer Data Base. Cancer. 2017; 123(9): 1653-61. PubMed Abstract | Publisher Full Text

18. Swaak-Kragten AT, de Wilt JH, Schmitz PI, et al:: Multimodality treatment for anaplastic thyroid carcinoma--treatment outcome in $\mathbf{7 5}$ patients. Radiother Oncol. 2009; 92(1): 100-4.

PubMed Abstract | Publisher Full Text

19. de Crevoisier R, Baudin E, Bachelot A, et al:: Combined treatment of anaplastic thyroid carcinoma with surgery, chemotherapy, and hyperfractionated accelerated external radiotherapy. Int J Radiat Oncol Biol Phys. 2004; 60(4): 1137-43.

PubMed Abstract | Publisher Full Text

20. Kumar A, Prasongsook N, Kasperbauer J, et al.: Outcomes in response to aggressive multi-modal therapy in anaplastic thyroid cancer: the mayo clinic experience. Thyroid. 2015; 25(Supplement 1): abstr 72.

21. Smallridge RC, Ain KB, Asa SL, et al:: American Thyroid Association guidelines for management of patients with anaplastic thyroid cancer. Thyroid. 2012; 22(11): 1104-39.

PubMed Abstract | Publisher Full Text

22. Kelly LM, Barila G, Liu P, et al.: Identification of the transforming STRN-ALK fusion as a potential therapeutic target in the aggressive forms of thyroid cancer. Proc Natl Acad Sci U S A. 2014; 111(11): 4233-8.

PubMed Abstract | Publisher Full Text | Free Full Text

23. Ritterhouse LL, Wirth LJ, Randolph GW, et al.: ROS1 Rearrangement in Thyroid Cancer. Thyroid. 2016; 26(6): 794-7. PubMed Abstract | Publisher Full Text

24. F Kunstman JW, Juhlin CC, Goh G, et al:: Characterization of the mutational landscape of anaplastic thyroid cancer via whole-exome sequencing. Hum $\mathrm{Mol}$ Genet. 2015; 24(8): 2318-29.

PubMed Abstract | Publisher Full Text | Free Full Text | F1000 Recommendation

25. Rosove MH, Peddi PF, Glaspy JA: BRAF V600E inhibition in anaplastic thyroid cancer. N Engl J Med. 2013; 368(7): 684-5. PubMed Abstract | Publisher Full Tex

26. Cabanillas ME, Busaidy NL, Khan SA, et al.: Molecular diagnostics and anaplastic thyroid carcinoma: The time has come to harvest the high hanging fruit. Int J Endocr Oncol. 2016; 3(3): 221-33. Publisher Full Text

27. Prager GW, Koperek O, Mayerhoefer ME, et al:: Sustained Response to Vemurafenib in a BRAF ${ }^{V 600 E}$-Mutated Anaplastic Thyroid Carcinoma Patient. Thyroid. 2016; 26(10): 1515-6. PubMed Abstract | Publisher Full Text

28. F Hyman DM, Puzanov I, Subbiah V, et al:: Vemurafenib in Multiple Nonmelanoma Cancers with BRAF V600 Mutations. N Engl J Med. 2015; 373(8) 726-36.

PubMed Abstract | Publisher Full Text | Free Full Text | F1000 Recommendation

29. Subbiah V, Kreitman RJ, Wainberg ZA, et al:: Dabrafenib and Trametinib Treatment in Patients With Locally Advanced or Metastatic BRAF V600-Mutant Anaplastic Thyroid Cancer. J Clin Oncol. 2018; 36(1): 7-13. PubMed Abstract | Publisher Full Text

30. Cabanillas ME, Busaidy NL, Zafereo M, et al:: Neoadjuvant vemurafenib in patients with locally advanced papillary thyroid cancer (PTC). European Thyroid Journal. 2017; 6(Suppl 1, abstr OP-06-39): 23-118.

31. F Drilon A, Siena S, Ou SI, et al:: Safety and Antitumor Activity of the Multitargeted Pan-TRK, ROS1, and ALK Inhibitor Entrectinib: Combined Results from Two Phase I Trials (ALKA-372-001 and STARTRK-1). Cancer Discov. 2017; 7(4): 400-9.

PubMed Abstract | Publisher Full Text | Free Full Text | F1000 Recommendation

32. $\mathrm{F}$ Godbert $\mathrm{Y}$, Henriques de Figueiredo B, Bonichon $\mathrm{F}$, et al.: Remarkable 
Response to Crizotinib in Woman With Anaplastic Lymphoma KinaseRearranged Anaplastic Thyroid Carcinoma. J Clin Oncol. 2015; 33(20): e84-7. PubMed Abstract | Publisher Full Text | F1000 Recommendation

33. F Lim SM, Chang H, Yoon MJ, et al: A multicenter, phase II trial of everolimus in locally advanced or metastatic thyroid cancer of all histologic subtypes. Ann Oncol. 2013; 24(12): 3089-94.

PubMed Abstract | Publisher Full Text | F1000 Recommendation

34. Lorch JH, Busaidy N, Ruan DT, et al:: A phase II study of everolimus in patients with aggressive RAI refractory (RAIR) thyroid cancer (TC). JCO. 2013; 21(suppl): abstr 6023 Reference Source

35. Schneider TC, de Wit D, Links TP, et al.: Everolimus in Patients With Advanced Follicular-Derived Thyroid Cancer: Results of a Phase II Clinical Trial. J Clin Endocrinol Metab. 2017; 102(2): 698-707. PubMed Abstract | Publisher Full Text

36. F Wagle N, Grabiner BC, Van Allen EM, et al.: Response and acquired resistance to everolimus in anaplastic thyroid cancer. N Engl J Med. 2014; 371(15): 1426-33.

PubMed Abstract | Publisher Full Text | Free Full Text | F1000 Recommendation

37. F Bible KC, Suman VJ, Menefee ME, et al:: A multiinstitutional phase 2 tria of pazopanib monotherapy in advanced anaplastic thyroid cancer. J Clin Endocrinol Metab. 2012; 97(9): 3179-84.

PubMed Abstract | Publisher Full Text | Free Full Text | F1000 Recommendation

38. F Savvides $\mathrm{P}$, Nagaiah G, Lavertu $\mathrm{P}$, et al.: Phase II trial of sorafenib in patients with advanced anaplastic carcinoma of the thyroid. Thyroid. 2013; 23(5): 600-4.

PubMed Abstract | Publisher Full Text | Free Full Text | F1000 Recommendation

39. F Sosa JA, Elisei R, Jarzab B, et al.: Randomized safety and efficacy study of fosbretabulin with paclitaxel/carboplatin against anaplastic thyroid carcinoma. Thyroid. 2014; 24(2): 232-40.

PubMed Abstract | Publisher Full Text | F1000 Recommendation

40. Sosa JA, Balkissoon J, Lu SP, et al.: Thyroidectomy followed by fosbretabulin (CA4P) combination regimen appears to suggest improvement in patient survival in anaplastic thyroid cancer. Surgery. 2012; 152(6): 1078-87. PubMed Abstract | Publisher Full Text

41. F Tahara M, Kiyota N, Yamazaki T, et al.: Lenvatinib for Anaplastic Thyroid Cancer. Front Oncol. 2017; 7: 25.

PubMed Abstract | Publisher Full Text | Free Full Text | F1000 Recommendation

42. F Chintakuntlawar AV, Rumilla KM, Smith CY, et al.: Expression of PD-1 and PD-L1 in Anaplastic Thyroid Cancer Patients Treated With Multimodal Therapy: Results From a Retrospective Study. J Clin Endocrinol Metab. 2017; 102(6): 1943-50.

PubMed Abstract | Publisher Full Text | F1000 Recommendation
43. F Ahn S, Kim TH, Kim SW, et al: Comprehensive screening for PD-L1 expression in thyroid cancer. Endocr Relat Cancer. 2017; 24(2): 97-106. PubMed Abstract | Publisher Full Text | F1000 Recommendation

44. $\mathrm{F}$ Wu H, Sun $\mathrm{Y}, \mathrm{Ye} \mathrm{H}$, et al:: Anaplastic thyroid cancer: outcome and the mutation/expression profiles of potential targets. Pathol Oncol Res. 2015; 21(3): 695-701.

PubMed Abstract | Publisher Full Text | F1000 Recommendation

45. F Bastman JJ, Serracino HS, Zhu Y, et al:: Tumor-Infiltrating T Cells and the PD-1 Checkpoint Pathway in Advanced Differentiated and Anaplastic Thyroic Cancer. J Clin Endocrinol Metab. 2016; 101(7): 2863-73. PubMed Abstract | Publisher Full Text | Free Full Text | F1000 Recommendation

46. Dadu RV, Para Cuentas ER, Rodriguez Canales J, et al:: Anaplastic thyroid cancer is a hot immunogenic environment: immunoprofiling of a large cohort of ATC tumors. Thyroid. 2016; 26(Supplement 1).

47. F Ryder M, Ghossein RA, Ricarte-Filho JC, et al.: Increased density of tumorassociated macrophages is associated with decreased survival in advanced thyroid cancer. Endocr Relat Cancer. 2008; 15(4): 1069-74. PubMed Abstract | Publisher Full Text | Free Full Text | F1000 Recommendation

48. F Kim DI, Kim E, Kim YA, et al:: Macrophage Densities Correlated with CXC Chemokine Receptor 4 Expression and Related with Poor Survival in Anaplastic Thyroid Cancer. Endocrinol Metab (Seoul). 2016; 31(3): 469-75. PubMed Abstract | Publisher Full Text | Free Full Text | F1000 Recommendation

49. Caillou B, Talbot $\mathrm{M}$, Weyemi $\mathrm{U}$, et al.: Tumor-associated macrophages (TAMs) form an interconnected cellular supportive network in anaplastic thyroid carcinoma. PLoS One. 2011; 6(7): e22567. PubMed Abstract | Publisher Full Text | Free Full Tex

50. F Gordon SR, Maute RL, Dulken BW, et al.: PD-1 expression by tumourassociated macrophages inhibits phagocytosis and tumour immunity. Nature. 2017; 545(7655): 495-9.

PubMed Abstract | Publisher Full Text | F1000 Recommendation

51. F Brauner $\mathrm{E}$, Gunda V, Vanden Borre $\mathrm{P}$, et al.: Combining BRAF inhibitor and anti PD-L1 antibody dramatically improves tumor regression and anti tumor immunity in an immunocompetent murine model of anaplastic thyroid cancer. Oncotarget. 2016; 7(13): 17194-211.

PubMed Abstract | Publisher Full Text | Free Full Text | F1000 Recommendation

52. Sandulache VC, Williams MD, Lai SY, et al:: Real-Time Genomic Characterization Utilizing Circulating Cell-Free DNA in Patients with Anaplastic Thyroid Carcinoma. Thyroid. 2017; 27(1): 81-7. PubMed Abstract | Publisher Full Text | Free Full Text

53. Cabanillas ME, Smith A, Williams MD, et al:: Utility of BRAF V600E Immunoperoxidase Stain in Cytology Preparations of Cell Block and Aspirate Smears in Thyroid Cancers. Eur Thyroid J. 2017; 6(Suppl 1): abstr P2-02-69. 


\section{Open Peer Review}

\section{Current Peer Review Status:}

\section{Editorial Note on the Review Process}

Faculty Reviews are review articles written by the prestigious Members of Faculty Opinions. The articles are commissioned and peer reviewed before publication to ensure that the final, published version is comprehensive and accessible. The reviewers who approved the final version are listed with their names and affiliations.

\section{The reviewers who approved this article are:}

\section{Version 1}

\section{Ashok R Shaha}

Head and Neck Service, Department of Surgery, Memorial Sloan Kettering Cancer Center, New York, NY, USA

Competing Interests: No competing interests were disclosed.

\section{Vera Tiedje}

Department of Endocrinology and Metabolism, University Hospital Essen and University DuisburgEssen, Essen, Germany

Competing Interests: No competing interests were disclosed.

\section{Ana O Hoff}

Department of Endocrinology, Instituto do Câncer do Estado de São Paulo, São Paulo, Brazil

Competing Interests: No competing interests were disclosed.

The benefits of publishing with F1000Research:

- Your article is published within days, with no editorial bias

- You can publish traditional articles, null/negative results, case reports, data notes and more

- The peer review process is transparent and collaborative

- Your article is indexed in PubMed after passing peer review

- Dedicated customer support at every stage

For pre-submission enquiries, contact research@f1000.com 